\title{
Different effects of (+)-borneol and (-)-borneol on the pharmacokinetics of osthole in rats following oral administration
}

\author{
DAN-DAN LUO ${ }^{1 *}$, XIAO-YING CHEN ${ }^{2 *}$, ZHEN-BIAO ZHANG $^{1}$, CHAO-YUE SUN $^{1}$, YI-FENG ZHENG $^{1}$, \\ YU-HONG LIU ${ }^{1}$, XIU-FEN WANG ${ }^{1}$, QI WANG ${ }^{3}$, JANIS YA-XIAN ZHAN ${ }^{1}$ and ZI-REN SU ${ }^{1}$ \\ ${ }^{1}$ School of Chinese Materia Medica, Guangzhou University of Chinese Medicine, Guangzhou, Guangdong 510006; \\ ${ }^{2}$ Laboratory of Cardiovascular Diseases, Guangdong Medical University, Zhanjiang, Guangdong 524001; \\ ${ }^{3}$ Institute of Clinical Pharmacology, Guangzhou University of Chinese Medicine, Guangzhou, Guangdong 510006, P.R. China
}

Received March 11, 2016; Accepted February 20, 2017

DOI: $10.3892 / \mathrm{mmr} .2017 .6502$

\begin{abstract}
Osthole is the primary active component of a number of herbal plants such as the Cnidium monnieri fruit. In traditional Chinese herb medicine, osthole is commonly used in combination with borneol to obtain improved pharmacological effects. The aim of the present study was to investigate the effect of borneol enantiomers on the pharmacokinetics of osthole. An appropriate high-performance liquid chromatography (HPLC) method was applied to determine the concentrations of osthole in plasma. Following oral administration of osthole alone or combined with borneol in rats, blood samples were collected and analyzed by HPLC. The results demonstrated that there were statistically significant differences in the pharmacokinetic parameters of osthole between osthole administration alone and co-administration with borneol. When combined with synthetic borneol, the $\mathrm{AUC}_{0-\mathrm{t}}$, $\mathrm{AUC}_{0-\infty}$ and $\mathrm{C}_{\max }$ of osthole increased by 48.153, 104.708 and $92.630 \%$, respectively, while the CL/F decreased by $51.251 \%$. When combined with (+)-borneol, the $\mathrm{AUC}_{0-\mathrm{t}}, \mathrm{AUC}_{0-\infty}$ and $\mathrm{C}_{\max }$ of osthole were increased by $61.561,78.167$, and $51.769 \%$, respectively, while the $\mathrm{CL} / \mathrm{F}$ decreased by $44.174 \%(\mathrm{P}<0.01)$. In addition, when combined with (-)-borneol, the $\mathrm{AUC}_{0-\mathrm{t}}$, $\mathrm{AUC}_{0-\infty}$ and $\mathrm{C}_{\max }$ of osthole increased by $115.856,167.786$ and $271.289 \%$, respectively, while the CL/F decreased by $60.686 \%$ $(\mathrm{P}<0.01)$. These results indicated that borneol may enhance gastrointestinal absorption and inhibit the metabolism of
\end{abstract}

Correspondence to: Ms. Janis Ya-Xian Zhan or Professor Zi-Ren $\mathrm{Su}$, School of Chinese Materia Medica, Guangzhou University of Chinese Medicine, 232 WaiHuan Dong Road, Guangzhou, Guangdong 510006, P.R. China

E-mail: zyx@gzucm.edu.cn

E-mail: suziren@gzucm.edu.cn

*Contributed equally

Key words: (+)-borneol, (-)-borneol, osthole, pharmacokinetics osthole. In addition, the promotional effect of (-)-borneol on the pharmacokinetic parameters of osthole was greater than that of (+)-borneol.

\section{Introduction}

Osthole [7-methoxy-8-(3-methyplent-2-enyl) coumarin; Fig. 1A], a poorly water-soluble natural coumarin, is the main active component of the Fructus Cnidii and Heracleum moellendorffii Hance plant species. Osthole has been confirmed to possess numerous beneficial bioactivities including anti-inflammatory (1), neuroprotection (2) and antiosteoporotic activities (3). In addition, osthole has beneficial effects in glioblastoma multiforme (4), diabetes and acute ischemic stroke $(5,6)$. Although osthole possesses many biological and pharmacological activities, the application of osthole in the clinic has been limited due to its poor bioavailability and low plasma concentration $(7,8)$, which results from rapid elimination by the CYP3A4 enzyme in the liver (9). In addition, osthole is excreted in the kidneys and bile, which rely on the excretory function of P-glycoprotein (10).

Borneol, which is widely used in herbal medicine, is a component in the essential oils of numerous spice berries including Lavandula, Thymus vulgaris and Rosmarinus officinalis Linnaeus (11-13). In the molecular structure of borneol there is one chiral carbon atom, which produces two optical isomers: (+)-Borneol and (-)-borneol (Fig. 1B). Synthetic borneol [a racemate composed of (+)- and (-)-borneol, isoborneol (Fig. 1A)] is increasingly being applied to replace (+)- and (-)-borneol as there is an unlimited source and it is relatively inexpensive. Borneol has additionally been used as a Chinese medicine exhibiting various bioactivities including sedation, anti-inflammation and antioxidant activity (14-16). Notably, according to Chinese medicine, borneol was considered as a 'guide' drug, regulating and mediating the delivery of other prescription drugs (17). Previous studies have confirmed that borneol enhances the bioavailability of other drugs through pharmacokinetic interactions, including the intestinal absorption of salvianolic acid B and Akebia saponin $(18,19)$, the distribution of danshensu to the eye (20) and nasal absorption 
of geniposide (21). Previous studies have identified the differences between (+)- and (-)-borneol in their interactions with cytochrome P450 enzyme and p-glycoprotein, which serve an important role in the absorption and elimination of drugs (22-24). These studies indicated that there may be differences between the pharmacokinetic interactions of (+)- and (-)-borneol. In traditional Chinese medicine, co-administration of borneol with herbal drugs containing osthole, including Angelica pubescens, Fructus cnidii and Libanotis buchtormensis (Fisch.) DC, was commonly used (25). In addition, borneol inhibits cytochrome $\mathrm{P} 450$ enzyme, which participates in the elimination of osthole (26). Collectively the evidence suggests that borneol may promote the bioavailability of osthole. However, the pharmacokinetic interactions between osthole and borneol have not been reported. In addition, to the best of our knowledge, there is no evidence demonstrating that (+)-borneol and (-)-borneol possess different effects in the pharmacokinetics of osthole. Therefore, the aim of the present study was to verify the effect of borneol on the pharmacokinetics of osthole and to investigate the differences between treatments with (+)- and (-)-borneol when co-administration with osthole.

\section{Materials and methods}

Chemicals and reagents. (+)-Borneol (98\% purity) was purchased from Shenzhen Oupeng Technology Co., Ltd. (Shenzhen, China). (-)-Borneol (98\% purity) was obtained from Guizhou Miaoyao Biotechnology Co., Ltd. (Tongren, Guizhou, China). Synthetic borneol (97\% purity) was purchased from Jian Shengda Fragrance Oils Co., Ltd. (Jian, China). Standard osthole and paeonol were obtained from Chengdu Purechem-Standard Co., Ltd. (Chengdu, Sichuan, China). Chromatographic pure methanol, ethyl acetate and other chemicals and reagents were obtained from Guangzhou Lubex Biological Technology Co., Ltd. (Guangzhou, Guangdong, China) and were of analytical grade.

Preparation of standard solutions and quality control $(Q C)$ samples. The stock solution of osthole was prepared by accurately weighing standard osthole, which was then dissolved and diluted with chromatographic pure methanol to obtain a series standard solutions with the following concentrations: 1, 5, 10, 20, 40 and $80 \mu \mathrm{g} / \mathrm{ml}$. Paeonol standard was weighed precisely to prepare the internal solution (IS) at a concentration of $2 \mu \mathrm{g} / \mathrm{ml}$. Quality control (QC) samples were prepared daily using three concentrations of osthole standard solutions (10, 40 and $80 \mu \mathrm{g} / \mathrm{ml})$. A total of $100 \mu \mathrm{l}$ standard solution was dried prior to the addition of $200 \mu \mathrm{l}$ blank blood plasma, followed by vortex-mixing for $3 \mathrm{~min}$. All of the solutions were maintained at $4^{\circ} \mathrm{C}$ prior to use.

Sample preparation. An aliquot of blood plasma (100 $\mu \mathrm{l})$ was added to $50 \mu \mathrm{l}$ IS solution and $500 \mu \mathrm{l}$ chromatographic pure methanol, then vortex-mixed for $3 \mathrm{~min}$. Following centrifugation for $10 \mathrm{~min}$ at $12,000 \mathrm{x} \mathrm{g}$ and $4^{\circ} \mathrm{C}$, the supernatant was transferred into a centrifuge tube and dried using nitrogen gas. The residue was re-dissolved with $100 \mu \mathrm{l}$ chromatographic pure methanol. Following vortex-mixing for $3 \mathrm{~min}$ and centrifugation for $10 \mathrm{~min}$ at $12,000 \mathrm{x} \mathrm{g}$ and $4^{\circ} \mathrm{C}$, the supernatant was filtered using a $0.22-\mu \mathrm{m}$ nylon membrane prior to analysis using high-performance liquid chromatography (HPLC).

HPLC-ultraviolet (UV) method. HPLC analysis was performed using a Shimadzu HPLC system (Shimadzu Corporation, Kyoto, Japan). The HPLC system consisted of a LC solution chromatographic workstation, two pumps and a UV detector (model no. SPD-20A). Separation was executed using a Diamonsil $\mathrm{C}_{18}$ column (particle size, $5 \mu \mathrm{m} ; 250 \times 4.6 \mathrm{~mm}$; Dikma Co., Beijing, China). The mobile phase consisted of (A) water and (B) acetonitrile [25/75 (v/v)], with a constant rate of $1 \mathrm{ml} / \mathrm{min}$ and the column temperature was maintained at $25^{\circ} \mathrm{C}$ during the whole analysis process. An aliquot (10 $\mu \mathrm{l})$ of plasma sample was analyzed by HPLC, and the content of osthole and IS were detected at a wavelength of $320 \mathrm{~nm}$.

Method validation. Specificity: The specificity study was completed by comparing chromatograms of blank plasma, blank plasma spiked with osthole and IS, and plasma samples obtained from rats following oral administration.

Linearity and sensitivity: A total of 6 concentrations of standard solutions $(1,5,10,20,40$ and $80 \mu \mathrm{g} / \mathrm{ml})$ were used for the calibration curve. The calibration curve was structured by the peak area ratio (Y) of osthole to IS vs. the spiked concentrations $(\mathrm{X})$ of the analysis with a $1 / \mathrm{X}^{2}$ weighted least square linear regressions.

Accuracy and precision: Three quality control (QC) samples were used to test the accuracy and precision, with five replicates of each concentration. The measured concentrations were calculated using the calibration curves obtained daily. Intra-day precision and accuracy were determined by repeated analysis $(n=3)$ of the QC samples in the same day. Inter-day precision and accuracy were evaluated by repeated analysis of the QC samples over 3 consecutive days. The precision was determined by the relative standard deviation (RSD \%) and the accuracy as the relative error (RE \%).

Extraction recovery: Extraction recovery was assessed by comparing the measured concentration vs. the spiked concentration in three QC samples $(\mathrm{n}=5)$.

Stability: The stability test was composed of a short-term, the freeze-thaw cycle and the long-term stability tests. Each test was conducted with three QCs $(n=3)$. The short-term stability test was performed by analysis of QC samples following storage at room temperature for $24 \mathrm{~h}$. Freeze-thaw cycle stability was assessed following three freeze-thaw cycles within 3 consecutive days. In each cycle, QC samples were reserved at $-80^{\circ} \mathrm{C}$ for $24 \mathrm{~h}$ and subsequently thawed at room temperature. After complete thawing, the samples were refrozen at $-80^{\circ} \mathrm{C}$ for $24 \mathrm{~h}$. The long-term stability test was evaluated by assaying samples following a period of 2 weeks of storage at $-80^{\circ} \mathrm{C}$.

Pharmacokinetic study. Male Sprague-Dawley (SD) rats ( $n=24$; weight, 290-310 g; age, 11-14 weeks) were purchased from the Animal Center of Guangzhou University of Chinese Medicine (Guangzhou, Guangdong, China). All SD rats were specifically pathogen-free and fed under standard conditions (a stable temperature at $24 \pm 1^{\circ} \mathrm{C}$ and a $12 / 12-\mathrm{h}$ light/dark cycle) for at least 7 days prior to the pharmacokinetics experiment. All animals were fasted, with access to water only, for $12 \mathrm{~h}$ 
prior to drug administration. Animal experiments were performed in accordance with procedures approved by the Animal Experimental Ethics Committee of Guangzhou University of Chinese Medicine (dSPF 2014 021), and the experimental protocols followed the 'Guide for the Care and Use of Laboratory Animals'. All drugs were dissolved in 5\% Tween-80 for the pharmacokinetic studies.

In the pharmacokinetics experiments, the SD rats were randomly divided into four groups $(n=6)$, each group received oral administration of osthole $(300 \mathrm{mg} / \mathrm{kg})$, and were then given the following treatments: The control group was given an oral dose with extra 5\% Tween-80 (400 mg/kg) and the (+)-borneol, (-)-borneol and synthetic borneol groups were given oral doses with an extra $400 \mathrm{mg} / \mathrm{kg}$ borneol. The dosage of borneol and osthole applied was based on that of a previous study (27). Blood samples were collected at 5, 15, 30, 45, 60, 90, 120, 240, 360,480 and 720 min following oral administration from the suborbital venous plexus of the rat eye socket vein. Following blood collection, the animals were sacrificed following anesthesia. The blood samples were centrifuged at 12,000 $\mathrm{x} g$ and $4^{\circ} \mathrm{C}$ for $10 \mathrm{~min}$. The supernatant (the blood plasma) was then transferred into a clean polypropylene tube and maintained in a refrigerator at $-20^{\circ} \mathrm{C}$ for subsequent analysis.

Data analysis. Pharmacokinetic analysis of osthole was performed based on a non-compartmental description of the data observed. All data were expressed as the mean \pm standard deviation. The primary kinetic parameters $\left(\mathrm{AUC}_{0-\mathrm{t}}, \mathrm{AUC}_{0-\infty}\right.$, $\mathrm{C}_{\max }, \mathrm{T}_{\max }, \mathrm{V}_{\mathrm{d}} / \mathrm{F}, \mathrm{CL} / \mathrm{F}$ and $\mathrm{t}_{1 / 2}$ ) were calculated using $\mathrm{The}$ Drug and Statistics software (version 2.11; Mathematical Pharmacology Professional Committee of China, Shanghai, China). The area under the plasma concentration-time curve (AUC) was calculated using the linear trapezoidal method. In addition, the maximum plasma concentration $\left(\mathrm{C}_{\max }\right)$ and the time to reach the maximum plasma concentration $\left(\mathrm{T}_{\max }\right)$ were obtained from the plasma concentration-time data. The differences between any two respective treatment groups were analyzed for significance by one-way analysis of variance followed by Duncan's multiple range test with SPSS software (version 19; IBM SPSS, Armonk, NY, USA). P<0.05 was considered to indicate a statistically significantly difference.

\section{Results}

Method validation. Specificity: The typical chromatograms observed are depicted in Fig. 2. There were no interference peaks near the retention time peaks of osthole $(8.488 \mathrm{~min})$ and paeonol (4.885 $\mathrm{min})$, with favorable resolution $(\mathrm{R}>1.5)$, which demonstrated that the selectivity of osthole and IS was favored in the HPLC method.

Linearity and sensitivity: The calibration curves calculated in the range, $1-80 \mu \mathrm{g} / \mathrm{ml}$, were linear for the analysis of osthole from rat plasma. A good linear relation was obtained for osthole $\left[\mathrm{Y}=0.0101 \mathrm{X}+0.0321\left(\mathrm{R}^{2}=0.997\right)\right]$.

Accuracy and precision: As presented in Table I, in the 3 QC samples, the intra-day precision ranged from 1.334-3.373\% (RSD) and the inter-day precision ranged from 1.316-3.702\% (RSD). Analytical accuracy varied from 97.144-101.926\%.

Extraction recovery: As presented in Table II, in the 3 QC samples, the recoveries were all between 94.447 and $101.185 \%$,

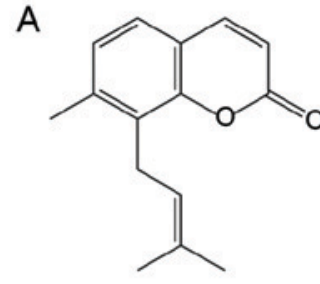

B
(+)-Borneol

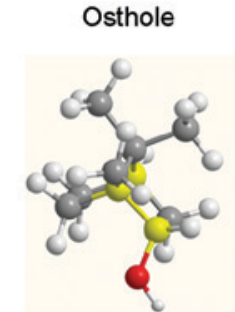

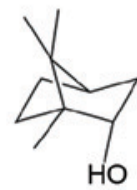

Borneol

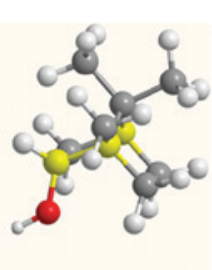

(-)-Borneol

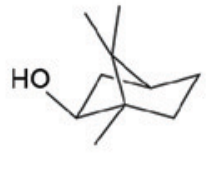

Isoborneol
Chiral carbon atom

Carbon atom

Hydrogen atom
Figure 1. (A) Chemical structures of osthole, borneol and isoborneol. (B) Three-dimension conformational chemical structures of (+)-borneol and (-)-borneol.

\section{A}

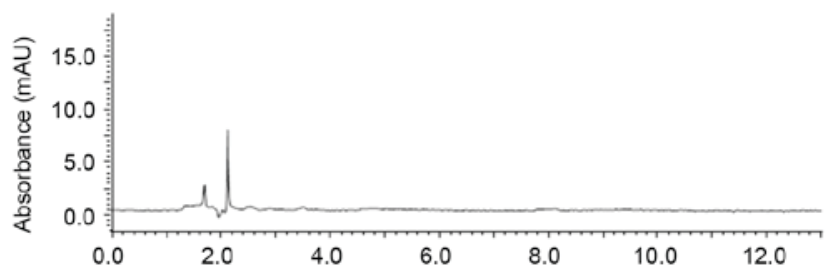

B

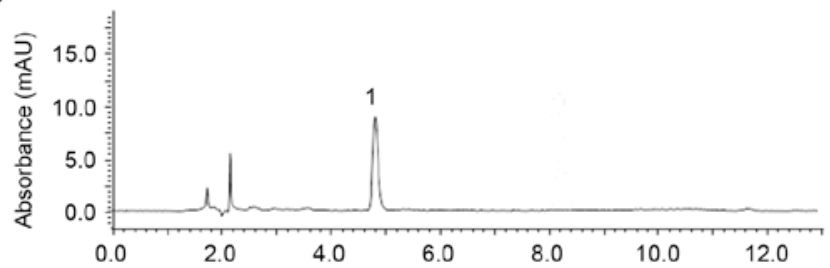

C

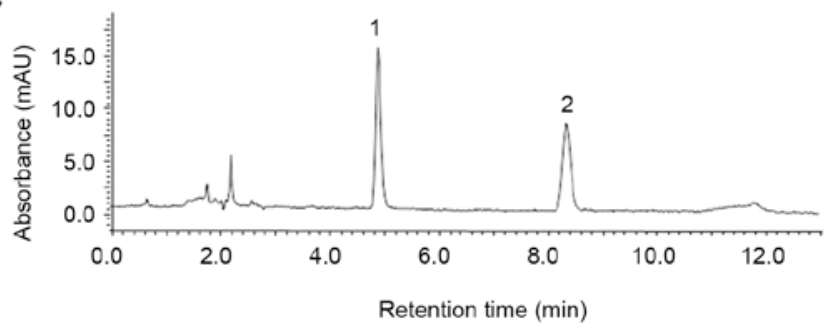

Figure 2. Typical chromatograms of (A) blank plasma, (B) blank plasma spiked with osthole and (C) plasma samples $0.25 \mathrm{~h}$ following oral administration. Chromatographic peaks: 1 , Paeonol; and 2, osthole.

and the RSDs were within 0.964 and $3.866 \%$. All of the results indicated that there was good repeatability of osthole following use as the sample pretreatment method.

Stability: As presented in Table III, the percentage of remaining osthole in the three stability tests was between 97.800 and $103.130 \%$, which indicated that the plasma samples were stable at $20^{\circ} \mathrm{C}$ for $24 \mathrm{~h},-20^{\circ} \mathrm{C}$ for 7 days and following three freeze-thaw cycles.

Pharmacokinetic study. The developed HPLC-UV method was applied to determine the plasma concentration of osthole 
Table I. The intra- and inter-day accuracy and precision scores of osthole in rat plasma.

\begin{tabular}{|c|c|c|c|c|}
\hline Day type & $\begin{array}{l}\text { Spiked concentration } \\
\qquad(\mu \mathrm{g} / \mathrm{ml})\end{array}$ & $\begin{array}{c}\text { Osthole, mean } \pm \mathrm{SD} \\
(\mu \mathrm{g} / \mathrm{ml})\end{array}$ & $\begin{array}{c}\text { Accuracy } \\
(\mathrm{RE}, \%)\end{array}$ & $\begin{array}{l}\text { Precision } \\
(\mathrm{RSD}, \%)\end{array}$ \\
\hline \multirow[t]{3}{*}{ Intra-day } & 5 & $4.857 \pm 0.019$ & 3.438 & 5.836 \\
\hline & 20 & $20.308 \pm 0.192$ & 1.796 & 1.501 \\
\hline & 80 & $81.541 \pm 0.419$ & 2.172 & 1.440 \\
\hline \multirow[t]{3}{*}{ Inter-day } & 5 & $4.857 \pm 0.065$ & 3.438 & 3.702 \\
\hline & 20 & $20.308 \pm 0.144$ & 1.796 & 1.469 \\
\hline & 80 & $81.541 \pm 0.741$ & 2.172 & 1.316 \\
\hline
\end{tabular}

Inter-day precision and accuracy ( $\mathrm{n}=5$ replicates each) were determined by repeated analysis of the three quality control samples on three consecutive days. The measured concentrations of osthole were calculated using the calibration curves obtained daily. Precision was determined by the percentage of RSD and the accuracy as the percentage of RE. The spiked concentrations represent the concentration of the blank plasma spiked with osthole and internal solution. SD, standard deviation; RSD, relative standard deviation; RE, relative error.

Table II. Recovery of osthole in rat plasma $(n=5)$.

\begin{tabular}{lrc}
\hline $\begin{array}{l}\text { Spiked concentration } \\
(\mu \mathrm{g} / \mathrm{ml})\end{array}$ & $\begin{array}{c}\text { Osthole, mean } \pm \mathrm{SD} \\
(\mu \mathrm{g} / \mathrm{ml})\end{array}$ & $\mathrm{RSD}(\%)$ \\
\hline 5 & $94.447 \pm 3.671$ & 3.886 \\
20 & $100.975 \pm 0.974$ & 0.964 \\
80 & $101.185 \pm 2.265$ & 2.238
\end{tabular}

Extraction recovery was assessed by comparing the measured concentration of osthole versus the spiked concentration in three QC samples ( $n=5$ replicates each). The spiked concentrations represent the concentration of the blank plasma spiked with osthole and internal solution. SD, standard deviation; RSD, relative standard deviation.

following oral administration of (+)-borneol, (-)-borneol and synthetic borneol. The kinetics curves of osthole in rats are displayed in Fig. 3 and the semi-log plot for the concentration-time profiles of osthole is presented in Fig. 4. The main pharmacokinetic parameters of osthole following oral administration are shown in Table IV, which were then compared (Fig. 5). The results demonstrated that the blood concentration and bioavailability of osthole were markedly enhanced following co-administration with borneol, however, the differences were significant between borneol enantiomers.

As presented in Table IV and Fig. 5, when compared with oral administration of osthole alone, there were significant differences in the primary kinetic parameters $\left(\mathrm{AUC}_{0-\infty}, \mathrm{C}_{\max }\right.$, $\mathrm{CL} / \mathrm{F}$ and $\mathrm{t}_{1 / 2}$ ) of osthole following co-administration with extra borneol. Firstly, when osthole was co-administered with (+)-borneol, (-)-borneol or synthetic borneol, the $\mathrm{AUC}_{0-\infty}$ of osthole was significantly enhanced by 78.167, 167.786 and $104.708 \%$, respectively, when compared with those in the osthole group alone. Secondly, the $\mathrm{C}_{\max }$ value of osthole was significantly promoted by $51.769,271.289$ and $92.635 \%$, respectively. Thirdly, the CL/F of osthole reduced by 44.174 , 60.686 and $51.251 \%$, respectively. Finally, the $t_{1 / 2}$ of osthole increased by $115.754,259.125$ and $378.592 \%$, respectively. In
Table III. Results of short-term stability, freeze-thaw cycles and long-term stability of osthole analysis in rat plasma.

\begin{tabular}{lccc}
\hline $\begin{array}{l}\text { Stability } \\
\text { test }\end{array}$ & $\begin{array}{c}\text { Spiked } \\
\text { concentration } \\
(\mu \mathrm{g} / \mathrm{ml})\end{array}$ & $\begin{array}{c}\text { Osthole, } \\
\text { mean } \pm \mathrm{SD} \\
(\mu \mathrm{g} / \mathrm{ml})\end{array}$ & \multicolumn{1}{c}{$\begin{array}{c}\text { Remaining } \\
(\%)\end{array}$} \\
\hline Short-term & 5 & $4.890 \pm 0.230$ & $97.800 \pm 4.608$ \\
stability & 20 & $20.297 \pm 0.043$ & $101.483 \pm 0.213$ \\
& 80 & $82.279 \pm 0.626$ & $102.849 \pm 0.782$ \\
Freeze-thaw & 5 & $5.008 \pm 0.057$ & $100.168 \pm 1.137$ \\
cycle & 20 & $20.434 \pm 0.213$ & $102.168 \pm 1.067$ \\
& 80 & $80.591 \pm 1.461$ & $100.739 \pm 1.826$ \\
Long-term & 5 & $4.922 \pm 0.113$ & $98.441 \pm 2.265$ \\
stability & 20 & $20.310 \pm 0.069$ & $101.551 \pm 0.343$ \\
& 80 & $82.509 \pm 0.100$ & $103.136 \pm 0.124$
\end{tabular}

The stability test was composed of a short-term stability test, the freeze-thaw cycle stability test and the long-term stability test. Each test was conducted with three quality control samples $(n=3)$. The spiked concentrations represent the concentration of the blank plasma spiked with osthole and internal solution.

addition, when osthole was co-administrated with (-)-borneol or synthetic borneol, the time to reach the $\mathrm{C}_{\max }$ was different to that of osthole alone.

Synthetic borneol was used as a reference substance in the present study. As presented in Table IV and Fig. 5, the key kinetic parameters $\left(\mathrm{AUC}_{0-\infty}, \mathrm{C}_{\max }, \mathrm{V}_{\mathrm{d}} / \mathrm{F}\right.$ and $\left.\mathrm{t}_{1 / 2}\right)$ of osthole in the (+)- and (-)-borneol groups were significantly different when compared with those in the synthetic borneol group. When compared with the synthetic borneol group, the $\mathrm{AUC}_{0-\infty}$, $\mathrm{C}_{\max }, \mathrm{V}_{\mathrm{d}} / \mathrm{F}$ and $\mathrm{t}_{1 / 2}$ values of osthole in the (+)-borneol group significantly reduced by $12.965,21.214,47.310$ and $54.919 \%$, respectively. However, when compared with synthetic borneol, the $\mathrm{AUC}_{0-\infty}$ and $\mathrm{C}_{\max }$ of osthole in the (-)-borneol group were promoted by 30.814 and $92.743 \%$, respectively. In addition, the $\mathrm{V}_{\mathrm{d}} / \mathrm{F}$ and $\mathrm{t}_{1 / 2}$ values decreased by 50.977 and $24.962 \%$, respectively and the time to reach $\mathrm{C}_{\max }$ was also reduced. 
Table IV. Main pharmacokinetic parameters of osthole following oral administration of osthole alone or combined with borneol.

\begin{tabular}{lccrc}
\hline Parameters & Control & Synthetic borneol & $(+)$-Borneol & $(-)$-Borneol \\
\hline $\mathrm{AUC}_{0-\mathrm{t}}\left(\mathrm{mg}^{*} \mathrm{~h} / \mathrm{l},\right)$ & $60.208 \pm 5.522$ & $89.200 \pm 2.394^{\mathrm{a}}$ & $97.272 \pm 5.017^{\mathrm{a}}$ & $129.961 \pm 6.679^{\mathrm{a}-}$ \\
$\mathrm{AUC}_{0-\infty}\left(\mathrm{mg}^{*} \mathrm{~h} / \mathrm{l},\right)$ & $61.617 \pm 5.959$ & $126.134 \pm 10.999^{\mathrm{a}}$ & $109.780 \pm 6.761^{\mathrm{a}, \mathrm{b}}$ & $165.001 \pm 2.268^{\mathrm{a}-\mathrm{c}}$ \\
$\mathrm{C}_{\max }(\mathrm{mg} / \mathrm{l})$ & $17.161 \pm 1.345$ & $33.059 \pm 2.048^{\mathrm{a}}$ & $26.046 \pm 2.351^{\mathrm{a}, \mathrm{b}}$ & $63.718 \pm 3.638^{\mathrm{a}-\mathrm{c}}$ \\
$\mathrm{T}_{\max }(\mathrm{h})$ & $0.500 \pm 0.000$ & $0.750 \pm 0.000$ & $0.542 \pm 0.368^{\mathrm{b}}$ & $0.250 \pm 0.000^{\mathrm{a}, \mathrm{b}}$ \\
$\mathrm{V}_{\mathrm{d}} / \mathrm{F}(\mathrm{l} / \mathrm{kg})$ & $13.943 \pm 3.089$ & $31.714 \pm 4.784^{\mathrm{a}}$ & $16.710 \pm 5.398^{\mathrm{a}}$ & $15.547 \pm 0.738^{\mathrm{a}, \mathrm{c}}$ \\
$\mathrm{CL} / \mathrm{F}(\mathrm{l} / \mathrm{h} / \mathrm{kg})$ & $4.911 \pm 0.524$ & $2.394 \pm 0.215^{\mathrm{a}}$ & $2.742 \pm 0.171^{\mathrm{a}}$ & $1.931 \pm 0.444^{\mathrm{a}, \mathrm{c}}$ \\
$\mathrm{t}_{1 / 2}(\mathrm{~h})$ & $1.950 \pm 0.083$ & $9.494 \pm 0.410^{\mathrm{a}}$ & $4.280 \pm 1.591^{\mathrm{a}, \mathrm{b}}$ & $7.124 \pm 0.814^{\mathrm{a}-\mathrm{c}}$ \\
\hline
\end{tabular}

Pharmacokinetic analysis of osthole was performed based on a non-compartmental description of the data observed. All data were expressed as the mean \pm standard deviation ( $\mathrm{n}=6 /$ group). The primary kinetic parameters of $\mathrm{AUC}_{0-\mathrm{t}}, \mathrm{AUC}_{0-\infty}, \mathrm{C}_{\max }, \mathrm{T}_{\max }, \mathrm{V}_{\mathrm{d}} / \mathrm{F}, \mathrm{CL} / \mathrm{F}$ and $\mathrm{t}_{1 / 2}$ were calculated using. The Drug and Statistics software. ${ }^{\mathrm{a}} \mathrm{P}<0.05$ vs. control group, ${ }^{\mathrm{b}} \mathrm{P}<0.05$ (+)- and (-)-borneol vs. synthetic borneol, and ${ }^{\mathrm{c}} \mathrm{P}<0.05$ (-)-borneol vs. (+)-borneol. $\mathrm{AUC}_{0-\mathrm{t}}$, area under the plasma concentration-time curve from time zero to time $\mathrm{t}$; $\mathrm{AUC}_{0-\infty}$, area under the plasma concentration-time curve from time zero to infinity; $\mathrm{C}_{\max }$, maximum (peak) plasma drug concentration; $\mathrm{T}_{\max }$, time to reach maximum (peak) plasma concentration following drug administration; $\mathrm{V}_{\mathrm{d}} / \mathrm{F}$, apparent volume of distribution after non-intravenous administration; CL/F, apparent total clearance of the drug from plasma after oral administration; $\mathrm{t}_{1 / 2}$, elimination half-life.

A

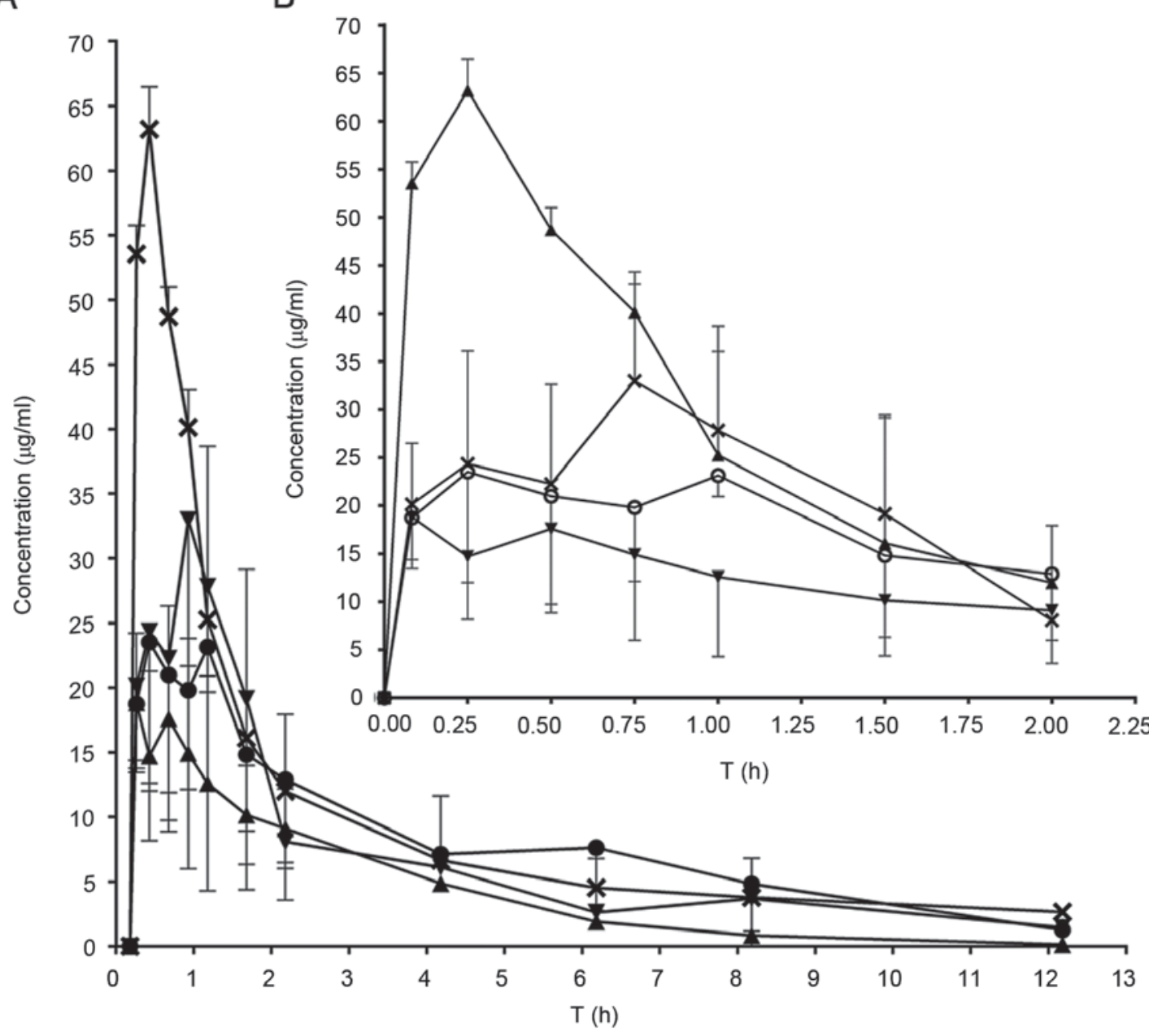

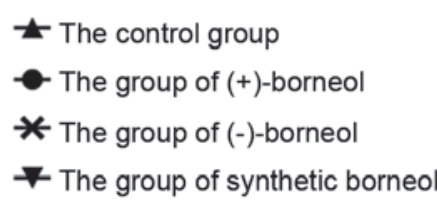

Figure 3. Mean plasma concentration vs. time profiles of osthole in rats administered osthole ( $300 \mathrm{mg} / \mathrm{kg}) \mathrm{alone}$ or co-administered with borneol (400 mg/ $\mathrm{kg}$ ) (A) 0-12 $\mathrm{h}$ and (B) 0-2 $\mathrm{h}$ following oral administration. Data are presented as the mean \pm standard deviation (n=6). 
A

B

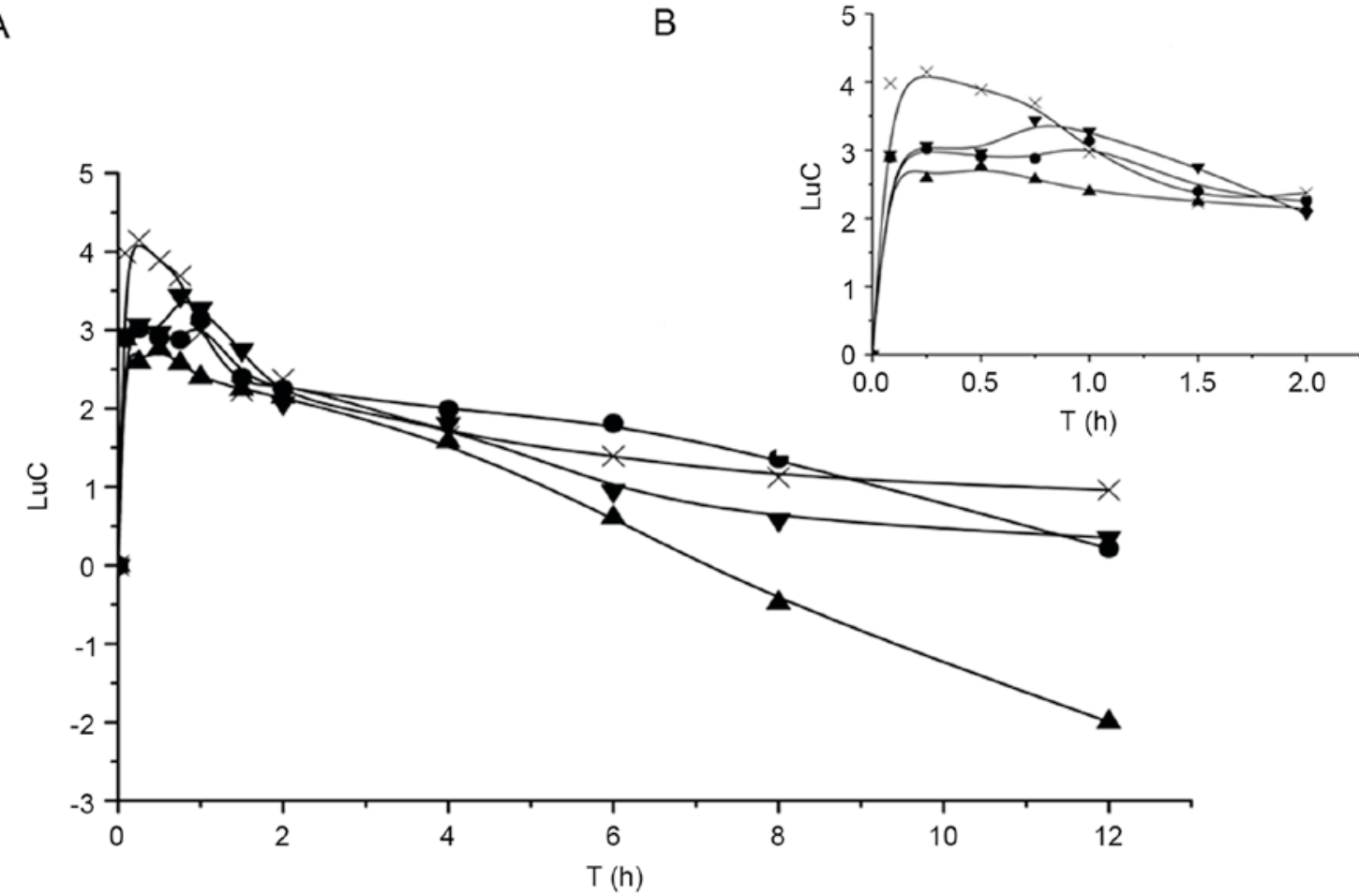

- The control group
The group of (+)-borneol

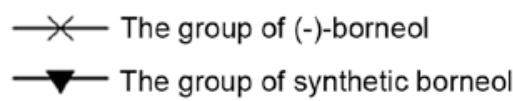

Figure 4. Semi-log plot for the concentration-time profiles of osthole in rats administered osthole $(300 \mathrm{mg} / \mathrm{kg})$ alone or co-administered with borneol (400 mg/kg) (A) 0-12 h and (B) 0-2 $\mathrm{h}$ following oral administration.

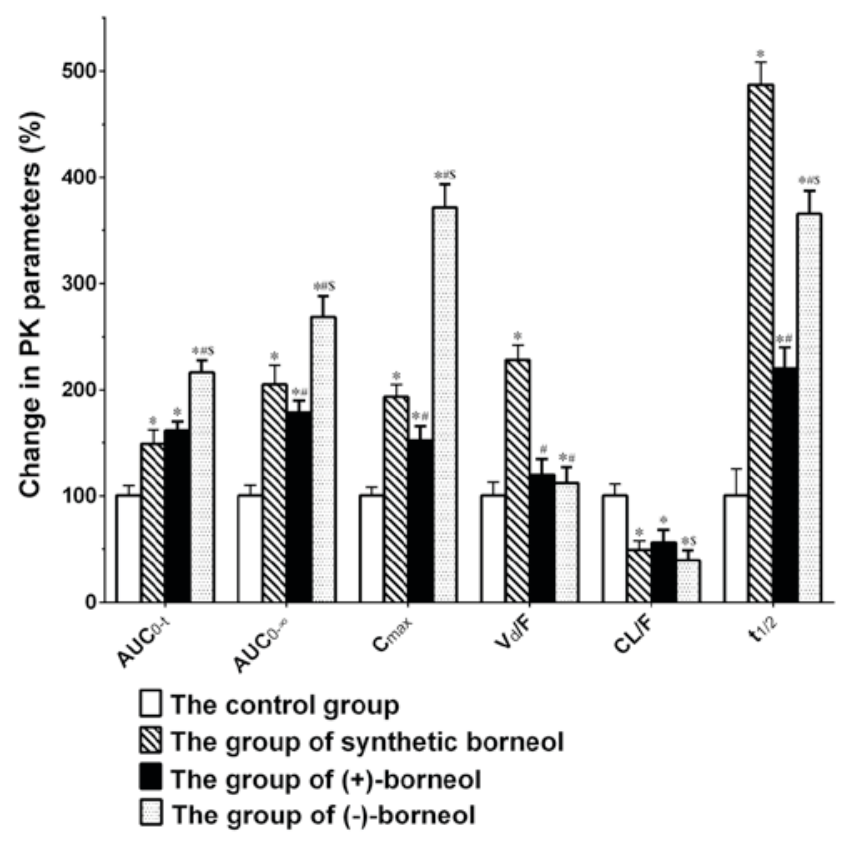

Figure 5. Percentage change in the main pharmacokinetic parameters of osthole, including the $\mathrm{AUC}_{0-\mathrm{t}}, \mathrm{AUC}_{0-\infty}, \mathrm{C}_{\max }, \mathrm{V}_{\mathrm{d}} / \mathrm{F}, \mathrm{CL} / \mathrm{F}$ and $\mathrm{t}_{1 / 2}$ compared with the control group. ${ }^{*} \mathrm{P}<0.05$ vs. control group; ${ }^{*} \mathrm{P}<0.05$ (+)- and (-)-borneol vs. synthetic borneol; ${ }^{\$} \mathrm{P}<0.05$ (-)-borneol vs. (+)-borneol. $\mathrm{AUC}_{0-t}$, area under the plasma concentration-time curve from time zero to time $\mathrm{t}$; $\mathrm{AUC}_{0-\infty}$, area under the plasma concentration-time curve from time zero to infinity; $\mathrm{C}_{\max }$, maximum (peak) plasma drug concentration; $\mathrm{V}_{\mathrm{d}} / \mathrm{F}$, apparent volume of distribution after non-intravenous administration; $\mathrm{CL} / \mathrm{F}$, apparent total clearance of the drug from plasma after oral administration; $\mathrm{t}_{1 / 2}$, elimination half-life.
(+)- and (-)-borneol had different effects on the bioavailability of osthole, as osthole co-administered with (-)-borneol was assimilated more rapidly. As presented in Table IV and Fig. 5, when compared with the (+)-borneol group , the $\mathrm{C}_{\max }$ of osthole in the (-)-borneol group was markedly enhanced by $144.640 \%$, with a significantly shorter $\mathrm{T}_{\max }$. In addition, the $\mathrm{CL} / \mathrm{F}$ of osthole in the (-)-borneol group was greatly decreased with a rate of $29.576 \%$, while the $\mathrm{AUC}_{0-\infty}$ value of osthole in the (-)-borneol group enhanced by $50.301 \%$.

\section{Discussion}

When focusing on the total pharmacokinetics trend of osthole treatment alone or co-administration with extra borneol, the kinetic curve could be interpreted as the fast absorption of osthole with a rapid post-absorption phase. The post-absorption phase can be subdivided into distribution and elimination phases, which are depicted in Fig. 4. The rapid absorption phase was observed from starting time to $\mathrm{T}_{\max }$. During this time, osthole was rapidly absorbed, which was in agreement with the results of a previous study (28). However, the absorption rate increased when an oral dose was given with extra borneol; the absorption rate was the fastest in the (-)-borneol group. The effect of borneol on promoting the absorption of oral drugs was widespread without a clear mechanism (29). During the distribution phase, blood concentrations reduced slowly due to the distribution and re-release of osthole into the tissues including the heart, liver, spleen, lungs and kidneys, which may lead to a higher plasma concentrations (7). In the 
elimination phase, osthole was eliminated quickly by the CYP3A4 enzyme in liver (9). However, the elimination rate decreased when osthole treatment was combined with borneol. The inhibitory effect of borneol on the CYP3A4 enzyme may induce this effect $(23,24)$.

In the control group treated with osthole only, the pharmacokinetic parameters of osthole were partially consistent with the results observed by Zheng et al (30), in which osthole also exhibited a low $\mathrm{C}_{\max }$, high $\mathrm{CL}$ and short $\mathrm{t}_{1 / 2}$ following oral administration. However, the primary kinetic parameters, $\mathrm{AUC}_{0-\infty}$ and $\mathrm{C}_{\text {max }}$, of osthole were enhanced following co-administration with extra borneol, while the $\mathrm{CL} / \mathrm{F}$ of osthole decreased. This result indicated that borneol may enhance gastrointestinal absorption of osthole and inhibit its metabolism. The increased absorption rate led to a higher $\mathrm{C}_{\max }$, this phenomenon was also observed in tetramethylpyrazine phosphate treatment with borneol (31). Previous studies have demonstrated that osthole was rapidly metabolized through ten phase I and three phase II metabolites in the hepatocyte by CYP3A4 enzyme $(9,32)$. (+)-Borneol, (-)-borneol and isoborneol all inhibit the CYP3A4 enzyme (24). The inhibition of CYP3A4 enzyme by borneol decreased CL/F (Fig. 4). This impaired elimination has also been observed in salvanic acid $\mathrm{B}$ and tetramethylpyrazine phosphate treatments when co-administrated with borneol $(18,31)$. Notably, the promoted $\mathrm{C}_{\max }$ and inhibited $\mathrm{CL} / \mathrm{F}$ values all contributed to the significantly enhanced $\mathrm{AUC}_{0-\infty}$ of osthole when combined with extra borneol.

Synthetic borneol was used as a reference substance in the present study. Synthetic borneol was composed of (+)-borneol, (-)-borneol and isoborneol. The proportion of $(+)$ - and (-)-borneol in synthetic borneol should not be $<55 \%$. According to previous studies, (+)-borneol, (-)-borneol and isoborneol have different effects on the CYP3A4 enzyme $(33,34)$. When compared with osthole combined with synthetic borneol, the $\mathrm{AUC}_{0-\infty}, \mathrm{C}_{\mathrm{max}}, \mathrm{V}_{\mathrm{d}} / \mathrm{F}$ and $\mathrm{t}_{1 / 2}$ of the (+)-borneol group were significantly decreased, which may be attributable to the weaker inhibitory effect on CYP3A4 enzyme and P-glycoprotein of (+)-borneol (22-24). In addition, in the (-)-borneol group, the $\mathrm{AUC}_{0-\mathrm{t}}, \mathrm{AUC}_{0-\infty}, \mathrm{C}_{\max }$ and $\mathrm{t}_{1 / 2}$ were significantly enhanced, while CL/F was diminished, compared with the synthetic borneol group. The enhanced $\mathrm{C}_{\max }$ may be a result of the strong promotional effect of (-)-borneol on absorption and the diminished CL/F may occur as a result of the greater inhibitory effect on CYP3A4 enzyme. All of these contributed to a higher $\mathrm{AUC}_{0-\mathrm{t}}$ and $\mathrm{AUC}_{0-\infty}$ in the (-)-borneol group when compared with that of the synthetic borneol, which has additionally been noted in the permeation of gardenia extract (35).

The influence of (-)-borneol on $\mathrm{AUC}_{0-\mathrm{t}}, \mathrm{AUC}_{0-\infty}, \mathrm{C}_{\max }$ and $\mathrm{CL} / \mathrm{F}$ of osthole was stronger than that of (+)-borneol, which may be due to the faster absorption and stronger inhibition of the CYP3A4 enzyme by (-)-borneol $(23,36)$. The different effects on the absorption rate and CYP3A4 enzyme of the two borneol enantiomers may be as a result of their different optical activities. As presented in Fig. 1B, (+)-borneol possesses the same chemical structure as (-)-borneol except for a hydroxyl oriented in the opposite direction to the geminal dimethyl bridge in chiral carbon atom. The biological activity of drugs is greatly associated with the optical activity. Enantiomers are considerably different in potency, pharmacological activity and pharmacokinetic profile, as the molecules with which they interact in biological systems are additionally optically active $(37,38)$. The different pharmacological activity between (+)-borneol and (-)-borneol are also observed when interacting with the $\gamma$-aminobutyric acid receptor (15).

In conclusion, to the best of our knowledge, this is the first study to demonstrate the enhanced effect of borneol on the blood concentration and bioavailability of osthole following oral administration in rats. In addition, there were significant differences between the borneol enantiomers when interacting with osthole, with (-)-borneol having a stronger promotional effect on the pharmacokinetic parameters of osthole.

\section{Acknowledgements}

The present study was supported by grants from the Hong Kong, Macao and Taiwan Science \& Technology Cooperation Program of China (grant no. 2014DFH30010), the Guangdong International Cooperation Project (grant no. 2013508102016), the Science and Technology Planning Project of Guangdong Province, China (grant nos. 2014A020221050, 2013B090600007, 2013B090600026 and 2012B090600007), the National Natural Science Foundation of China (grant no. 81503318), Guangzhou University of Chinese Medicine Youth Elite Project (QNYC20170106) and Guangdong Province Universities and Colleges Pearl River Scholar Funded Scheme (2011).

\section{References}

1. Liao PC, Chien SC, Ho CL, Wang EI, Lee SC, Kuo YH, Jeyashoke N, Chen J, Dong WC, Chao LK and Hua KF: Osthole regulates inflammatory mediator expression through modulating $\mathrm{NF}-\kappa \mathrm{B}$, mitogen-activated protein kinases, protein kinase $\mathrm{C}$, and reactive oxygen species. J Agr Food Chem 58: 10445-10451, 2010.

2. Chen T, Liu W, Chao X, Qu Y, Zhang L, Luo P, Xie K, Huo J and Fei Z: Neuroprotective effect of osthole against oxygen and glucose deprivation in rat cortical neurons: Involvement of mitogen-activated protein kinase pathway. Neuroscience 183: 203-211, 2011.

3. Zhang Q, Qin L, He W, Van Puyvelde L, Maes D, Adams A, Zheng $\mathrm{H}$ and De Kimpe N: Coumarins from Cnidium monnieri and their antiosteoporotic activity. Planta Med 73: 13-19, 2007.

4. Lin YC, Lin JC, Hung CM, Chen Y, Liu LC, Chang TC, Kao JY, Ho CT and Way TD: Osthole inhibits insulin-like growth factor-1-induced epithelial to mesenchymal transition via the inhibition of PI3K/Akt signaling pathway in human brain cancer cells. J Agr Food Chem 62: 5061-5071, 2014.

5. Lee WH, Lin RJ, Lin SY, Chen YC, Lin HM and Liang YC: Osthole enhances glucose uptake through activation of AMP-activated protein kinase in skeletal muscle cells. J Agr Food Chem 59: 12874-12881, 2011.

6. Chao XD, Zhou J, Chen T, Liu W, Dong W, Qu Y, Jiang X, Ji X, Zhen $\mathrm{H}$ and Fei Z: Neuroprotective effect of osthole against acute ischemic stroke on middle cerebral ischemia occlusion in rats. Brain Res 1363: 206-211, 2010.

7. Shi JF, Chen Q, Yang W, Yang HP, Liu J, Wang XM and He X: Comparative study of pharmacokinetics and tissue distribution of osthole in rats after oral administration of pure osthole and Libanotis buchtormensis supercritical extract. J Ethnopharmacol 145: 25-31, 2013.

8. Zhao G, Peng C, Du W and Wang S: Pharmacokinetic study of eight coumarins of Radix Angelicae Dahuricae in rats by gas chromatography-mass spectrometry. Fitoterapia 89: 250-256, 2013.

9. Zhang LF, Hu X, Wang P and Zhang L: Metabolism of osthol in isolated hepatocytes of rat. Yao Xue Xue Bao 44: 1131-1135, 2009 (In Chinese). 
10. Ambudkar SV, Kimchi Sarfaty C, Sauna ZE and Gottesman MM: P-glycoprotein: From genomics to mechanism. Oncogene 22: 7468-7485, 2003.

11. Hassanpouraghdam MB, Hassani A, Vojodi L, Hajisamadi Asl B and Rostami A: Essential oil constituents of Lavandula officinalis Chaix. from Northwest Iran. J Agr Food Chem 22: 167-171, 2011

12. Angioni A, Barra A, Cereti E, Barile D, Coïsson JD, Arlorio M, Dessi S, Coroneo V and Cabras P: Chemical composition, plant genetic differences, antimicrobial and antifungal activity investigation of the essential oil of Rosmarinus officinalis L. J Agr Food Chem 52: 3530-3535, 2004.

13. Nezhadali A, Navavi M and Rajabian M: Chemical composition of the essential oil of Thymus vulgaris L. from Iran. J Essent Oil Bear Pl 15: 368-372, 2012.

14. Harish R, Divakar S, Srivastava A and Shivanandappa T: Isolation of antioxidant compounds from the methanolic extract of the roots of Decalepis hamiltonii (Wight and Arn.). J Agric Food Chem 53: 7709-7714, 2005.

15. Granger RE, Campbell EL and Johnston GA: (+)- And (-)-borneol: Efficacious positive modulators of GABA action at human recombinant alphalbeta2gamma2L GABA(A) receptors. Biochem pharmacol 69: 1101-1111, 2005.

16. Mihara S and Shibamoto T: The role of flavor and fragrance chemicals in TRPA1 (transient receptor potential cation channel, member A1) activity associated with allergies. Allergy Asthma Clin Immunol 11: 11, 2015.

17. Lai XJ, Zhang L, Li JS, Liu HQ, Liu XH, Di LQ, Cai BC and Chen LH: Comparative pharmacokinetic and bioavailability studies of three salvianolic acids after the administration of Salviae miltiorrhizae alone or with synthetical borneol in rats. Fitoterapia 82: 883-888, 2011.

18. Ren-Zhong W, Yan-Yan X, Yan-Ping L, Mao-Jin Z and Chang-Xiao L: Enhancing effects of different dosages of borneol on pharmacokinetics of salvanic acid B after oral administration to rats. J Asian Nat Prod Res 14: 538-544, 2012.

19. Zhou Y, Li W, Chen L, Ma S, Ping L and Yang Z: Enhancement of intestinal absorption of akebia saponin $\mathrm{D}$ by borneol and probenecid in situ and in vitro. Environ Toxicol Pharmacol 29: 229-234, 2010.

20. Li Z, Sun D, Yang H, Liu X, Luan L, Bai J and Cui H: Effect of borneol on the distribution of danshensu to the eye in rabbit via oral administration. Curr Eye Res 35: 565-572, 2010.

21. Lu Y, Chen X, Du S, Wu Q, Yao Z and Zhai Y: The in situ and in vivo study on enhancing effect of borneol in nasal absorption of geniposide in rats. Arch Pharm Res 33: 691-696, 2010.

22. He H, Shen Q and Li J: Effects of borneol on the intestinal transport and absorption of two P-glycoprotein substrates in rats. Arch Pharm Res 34: 1161-1170, 2011.

23. Jinno N, Tagashira M, Tsurui K and Yamada S: Contribution of cytochrome P450 and UDT-glucuronosyltransferase to the metabolism of drugs containing carboxylic acid groups: Risk assessment of acylglucuronides using human hepatocytes. Xenobiotica 44: 677-686, 2014
24. Seo KA, Kim H, Ku HY, Ahn HJ, Park SJ, Bae SK, Shin JG and Liu KH: The monoterpenoids citral and geraniol are moderate inhibitors of CYP2B6 hydroxylase activity. Chem Biol Interact 174: 141-146, 2008.

25. Dai DZ, Du GM, Wang J, Jiang JJ, Chen ZM and Zhang ZC Comparison of penetration enhancer on skin of azone and borneolum to osthole. J Jinling Institute Technol 24: 90-93, 2008.

26. Hu DH, Wang YG, Chen ZW, MA ZC, Liang QD, Xiao CY, Tan HL, Tang XL, Li H, Shen GL, et al: Effect of compound Danshen Dripping Pills on rat hepatic cytochrome P450. Chin J Pharmacol Toxicol 27: 678-684, 2013.

27. Cai Z, Hou S, Li Y, Zhao B, Yang Z, Xu S and Pu J: Effect of borneol on the distribution of gastrodin to the brain in mice via oral administration. J Drug Target 16: 178-184, 2008.

28. Yun F, Kang A, Shan J, Zhao X, Bi X and Di L: A rapid and sensitive LC-MS/MS method for the determination of osthole in rat plasma: Application to pharmacokinetic study. Biomed Chromatogr 27: 676-680, 2013.

29. Zhang HY, W KW, Qian L, et al: Effect of borneol on promoting absorption of oral drugs. Chin J Exp Tradit Med Formulae 18: 294-297, 2012 (In Chinese)

30. Zheng LQ,Z DS and Liu JH: The study on the distribution in tissue of osthole in rats by the RP-HPLC. Chin Pharm J 11: 1666-1668, 2006 (In Chinese).

31. Yan-Yu X, Qi-Neng P and Zhi-Peng C: The enhancing effect of synthetical borneol on the absorption of tetramethylpyrazine phosphate in mouse. Int J Pharm 337: 74-79, 2007.

32. Lv X, Wang CY, Hou J, Zhang BJ, Deng S, Tian Y, Huang SS, Zhang HL, Shu XH, Zhen YH, et al: Isolation and identification of metabolites of osthole in rats. Xenobiotica 42: 1120-1127, 2012.

33. Kim H, Kim KB, Ku HY, Park SJ, Choi H, Moon JK, Park BS, Kim JH, Yea SS, Lee CH, et al: Identification and characterization of potent CYP2B6 inhibitors in woohwangcheongsimwon suspension, an herbal preparation used in the treatment and prevention of apoplexy in Korea and China. Drug Metab Dispos 36: 1010-1015, 2008.

34. Yu B, Ruan M, Dong X, Yu Y and Cheng H: The mechanism of the opening of the blood-brain barrier by borneol: A pharmacodynamics and pharmacokinetics combination study. J Ethnopharmacol 150: 1096-1108, 2013.

35. Lu Y, Du S, Yao Z, Zhao P and Zhai Y: Study on natural borneol and synthetic borneol affecting mucosal permeability of gardenia extract. Zhongguo Zhong Yao Za Zhi 34: 1207-1210, 2009 (In Chinese).

36. Zhou JW: The influence and mechanism of borneol, synthetic borneol and menthol on the P-glycoprotein. $\mathrm{PhD}$ dissertation, Nanjing Normal University. China Knowledge Resource Integrated Database, 6, 2011 (In Chinese).

37. Caldwell J: Do single enantiomers have something special to offer? Hum Psychopharm Clin 16: S67-S71, 2001.

38. Islam MR, Mahdi JG and Bowen ID: Pharmacological importance of stereochemical resolution of enantiomeric drugs. Drug Saf 17: $149-165,1997$. 